\title{
Evaluation of the Particle Aerosolization from n-TiO Photocatalytic Nanocoatings under Abrasion
}

\author{
Neeraj Shandilya, ${ }^{1,2}$ Olivier Le Bihan, ${ }^{1}$ Christophe Bressot, ${ }^{1}$ and Martin Morgeneyer $^{2}$ \\ ${ }^{1}$ Institut National de l'Environnement Industriel et des Risques (INERIS), Parc Technologique Alata BP 2, \\ 60550 Verneuil-en-Halatte, France \\ ${ }^{2}$ Université de Technologie de Compiègne (UTC), rue Roger Coutollenc, 60200 Compiègne, France \\ Correspondence should be addressed to Neeraj Shandilya; neeraj.shandilya@utc.fr
}

Received 20 December 2013; Accepted 27 March 2014; Published 6 May 2014

Academic Editor: Godwin Ayoko

Copyright (C) 2014 Neeraj Shandilya et al. This is an open access article distributed under the Creative Commons Attribution License, which permits unrestricted use, distribution, and reproduction in any medium, provided the original work is properly cited.

\begin{abstract}
A parametric study on the release of titanium dioxide $\left(\mathrm{TiO}_{2}\right)$ nanoparticles from two commercial photocatalytic nanocoatings is carried out. For this, abrasion tests are performed on them. The formed aerosols are characterized by their number concentration, particle size distribution, individual particle shape, size, and chemical composition. The two nanocoatings appear to exhibit contrastingly opposite behavior with respect to the number concentration of the released particles. Having irregular shapes, the released particles are found to have unimodal size distributions with 1.5-3.5\% (in mass) of Ti content. However, no free nanoparticles of $\mathrm{TiO}_{2}$ were found. Distinct phases during the particle number concentration evolution with time are also discussed and evaluated. Two quantities- $(\Delta C / \Delta t)_{\mathrm{I}}$ and $T_{\mathrm{II}}$-are identified as the important indicators to qualitatively measure the resistance strength and hence the concentration of the released particles from a nanocoating during stress application.
\end{abstract}

\section{Introduction}

Photocatalytic nanocoatings are the special type of coatings that accelerate the reaction of forming activated oxygen from water or oxygen in the air. It accomplishes this formation by capturing ultraviolet light in the presence of photocatalyst titanium dioxide $\left(\mathrm{TiO}_{2}\right)$ nanoparticles $[1,2]$. The formed activated oxygen is strong enough to oxidize and decompose organic materials and kill bacteria. As a result, these nanocoatings impart self-cleaning, air purifying, antibacterial, odor destructive, and super hydrophilic and antistatic (resistance of the static adsorption of small dust particles) properties to the surfaces on which they are applied. Such advantages have rendered their increasing use in construction or masonry applications like walls, pavements, and so forth [1-3]. However, during their lifecycle, these nanocoatings are subjected to various mechanical stresses in the form of the handling or processing of the parts coated with them [4-10]. This may result in their disintegration and the $\mathrm{TiO}_{2}$ nanoparticles may start to get released in air in the form of aerosol [11, 12]. Upon exposure, these released $\mathrm{TiO}_{2}$ nanoparticles may interact with the human organism through inhalation or dermal contacts and get deposited inside the body. Various toxicological studies have demonstrated toxic effects of some types of $\mathrm{TiO}_{2}$ nanoparticles in this case [13-15]. In spite of this, there is no sufficient information in the literature about the possible release of nanoparticles from photocatalytic nanocoatings. To better understand this, nanoparticle aerosol release evaluation is critical.

The study presented here aims to evaluate aerosol particle release or aerosolization from two commercial photocatalytic nanocoatings having nanoparticles of $\mathrm{TiO}_{2}$. For simulating the stress conditions to which such coatings are subjected to, their abrasion is done. An experimental set-up is developed where the particles, after getting generated from abrasion, are characterized by aerosol measurement devices both in qualitative and semiquantitative ways.

\section{Materials and Method}

2.1. Surface Coating Material. For the study, two different commercially available photocatalytic nanocoatings were chosen. The details on the material properties are provided in 
TABLE 1: Material properties of the two nanocoatings (data provided by the manufacturers).

\begin{tabular}{lccc}
\hline Properties & Nanocoating 1 & Nanocoating 2 & Uncoated brick \\
\hline Main composition & Nanotitanium Dioxide & Nanotitanium dioxide & $\mathrm{Al}, \mathrm{Si}, \mathrm{Ca}$ \\
Crystallite structure & Anatase & Anatase & - \\
Average primary particle size & $<8 \mathrm{~nm}$ & $<40 \mathrm{~nm}$ & $7 \mu \mathrm{m}$ (r.m.s. roughness) \\
Coagulation index & $\sim 2$ & $\sim 4$ & - \\
Appearance & Pale white liquid & Yellowish transparent liquid & Yellow \\
Dispersant & Water-based & Water-based & - \\
$\mathrm{TiO}_{2}$ vol. $\%$ & 1.1 & 1 & - \\
\hline
\end{tabular}

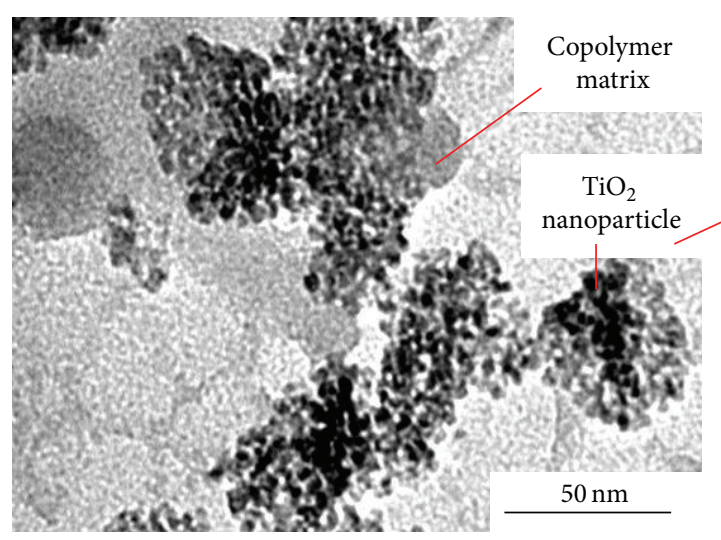

(a)

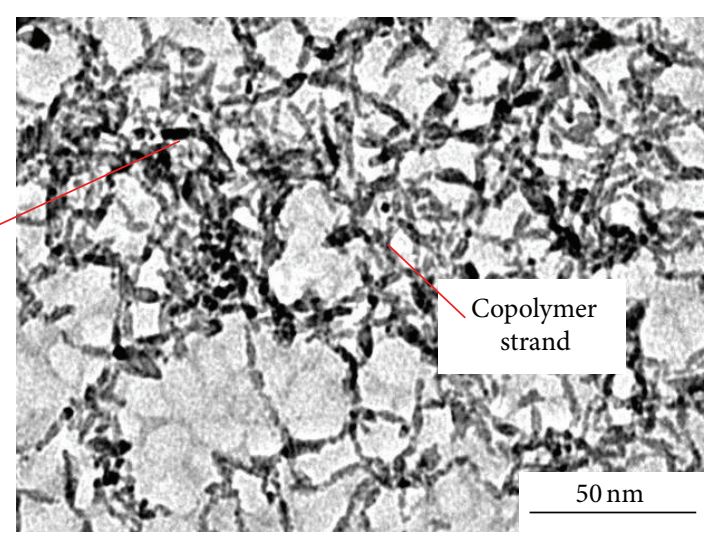

(b)

Figure 1: Microscopic analyses of the morphology of the nanoparticles present in the (a) nanocoating 1 and (b) nanocoating 2.

Table 1 . The substrate chosen for the nanocoating application was a masonry brick $(11 \mathrm{~cm} \times 5 \mathrm{~cm} \times 5 \mathrm{~cm}$; Leopard brick, Ref: 901796, Castorama). It is basically an aluminosilicate brick which is frequently used in constructing façades, house walls, stairs, and so forth.

To evaluate the elemental composition and the constituent nanoparticles' morphology of the two nanocoatings, a transmission electron microscopy (TEM; Model CM12; Philips, The Netherlands) analysis was done. For this, two separate $1 \%$ (by volume) diluted solutions of the two nanocoatings were prepared. One drop ( $8 \mu \mathrm{L}$ approximately) was taken from each diluted solution and was deposited on TEM copper mesh grids (Model S143-3; Quantifoil Micro Tools GmbH Germany). These mesh grids were made hydrophilic by their plasma treatment-0.1 mbar, $45 \mathrm{~mA}, 3 \mathrm{~min}$-(Model K100X, Glow Discharge, Emitech, Quorum Technologies Ltd. UK) prior to drop deposition. After the deposition, the grids were then allowed to dry in a closed chamber so that the water content gets evaporated and the $\mathrm{TiO}_{2}$ nanoparticles rest deposited on the grid.

In Figures 1(a) and 1(b), TEM images of the dried grids are shown. In Figure 1(a), the two phase agglomerates of the deposited particles from nanocoating 1 can be observed. These two phases are believed to be contributed by the copolymer (in grey color) and $\mathrm{TiO}_{2}$ nanoparticles (in pitch black color). The average $\mathrm{TiO}_{2}$ particle size is measured to be $8 \pm 4 \mathrm{~nm}$. However, in Figure 1(b), a network of stranded like structures from nanocoating 2 can be seen in which $\mathrm{TiO}_{2}$ nanoparticles (appearing as small black chunks) are believed to be embedded in copolymer strands. With a two phased structure, the average $\mathrm{TiO}_{2}$ particle size is measured to be $25 \pm$ $17 \mathrm{~nm}$. The energy-dispersive X-ray analysis (EDX; Model Xmax; Oxford Instruments UK) of the elemental composition of both nanocoatings shows similar chemical compositions, that is, C (60 to $65 \%$ in mass), $\mathrm{O}$ (15 to $20 \%$ in mass), Ti (10 to $15 \%$ in mass), $\mathrm{Si}$ ( 0 to $2 \%$ in mass), and traces of $\mathrm{Al}(<1 \%$ in mass).

The substrate surface preparation and the nanocoating application were done according to the technical data sheet recommended by the nanocoating manufacturers (i.e., degreased using brush and ethanol soaked paper, dry, and dust free surfaces; use of a high volume low pressure spray during coating; $25^{\circ} \mathrm{C}$ of ambient temperature). Different coating samples were prepared with two and four layers of both nanocoatings.

2.2. Abrasion Process. The standard Taber linear abrasion apparatus (Model 5750; Taber Inc. USA) was used for the abrasion of the nanocoatings. The apparatus is referenced in numerous internationally recognized test standards [1618]. This apparatus is already being used in industries for analyzing the performance of products like paint, coating, metal, paper, textile, and so forth, during the application of a mechanical stress [19]. The stress being applied through Taber also corresponds to the typical one applied to surface coatings in a domestic setting, for example, walking with shoes and displacement of different objects $[4,7]$. It incorporates 
TABLE 2: Experimental parameters (repetition of the tests: 3 times).

\begin{tabular}{|c|c|c|c|c|c|c|c|c|}
\hline \multirow{2}{*}{ Test sample } & \multirow{2}{*}{$\begin{array}{l}\text { Number of layers of } \\
\text { nanocoating (NOL) }\end{array}$} & \multicolumn{3}{|c|}{ Normal load } & \multirow{2}{*}{ Abradant } & \multirow{2}{*}{$\begin{array}{l}\text { Stroke length } \\
\quad(\mathrm{mm})\end{array}$} & \multirow{2}{*}{$\begin{array}{c}\text { Abrasion } \\
\text { speed (cpm) }\end{array}$} & \multirow{2}{*}{$\begin{array}{c}\text { Number o } \\
\text { cycles }\end{array}$} \\
\hline & & $6 \mathrm{~N}$ & $7.5 \mathrm{~N}$ & $10.5 \mathrm{~N}$ & & & & \\
\hline Uncoated (reference) & 0 & $\mathrm{X}$ & $\mathrm{X}$ & $\mathrm{X}$ & \multirow{5}{*}{$\mathrm{H} 38$} & \multirow{5}{*}{76} & \multirow{5}{*}{60} & \multirow{5}{*}{600} \\
\hline \multirow{2}{*}{ Nanocoating 1} & 2 & $\mathrm{X}$ & $\mathrm{x}$ & $\mathrm{X}$ & & & & \\
\hline & 4 & $\mathrm{X}$ & $\mathrm{X}$ & $\mathrm{X}$ & & & & \\
\hline \multirow{2}{*}{ Nanocoating 2} & 2 & $\mathrm{X}$ & $\mathrm{x}$ & $\mathrm{x}$ & & & & \\
\hline & 4 & $\mathrm{X}$ & $\mathrm{X}$ & $\mathrm{X}$ & & & & \\
\hline
\end{tabular}

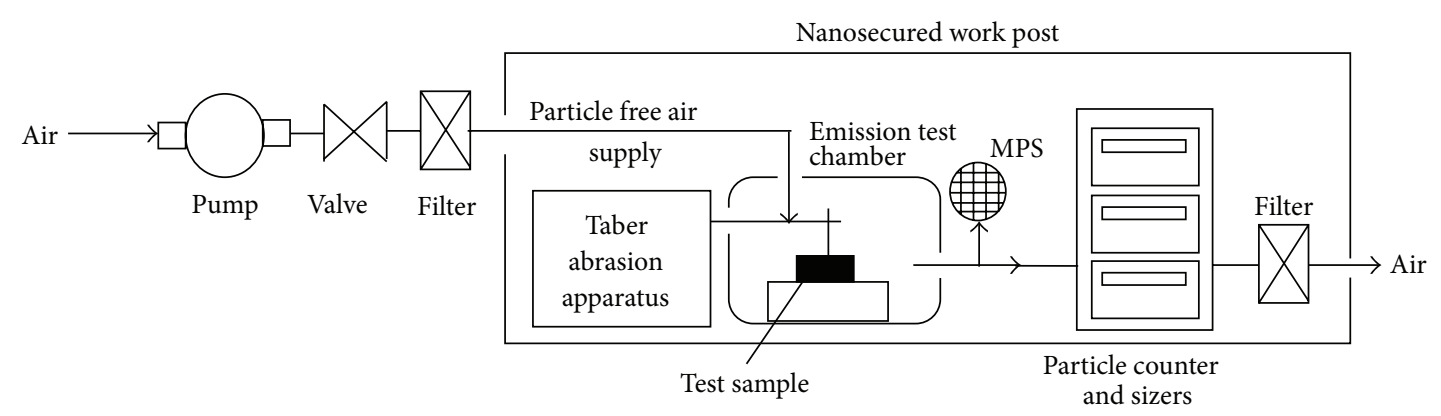

FIGURE 2: Experimental set-up.

a motor driven horizontal arm/bar that displaces an abradant in a back and forth linear motion over the test sample. The abrasion is caused by the friction at the contact surface between the surfaces of the abradant and the sample. Via a vertical shaft, a known weight is mounted on the top of the abradant which shall be referred to as the Normal Load in the text. The abrasiveness can be varied by changing the type of the abradant and normal load value. It is imperative to apply a reproducible and standardized stress on the test samples for reproducible tests. This has been ensured through preliminary tests and contextual literature survey on the optimal adjustment of the Taber abrasion apparatus [20-24].

2.3. Parameters Studied. In total, the effect of three experimental parameters on the concentration of released aerosol particles was studied: type of the nanocoating (i.e., nanocoatings 1 and 2), normal load (i.e., 6, 7.5, and $10.5 \mathrm{~N}$ ), and number of layers of the nanocoating (i.e., 2 and 4 ).

The details can be seen in Table 2. An uncoated brick sample was also used for the reference. A Taber H38 nonresilient vitrified clay-carborundum abradant was used during the whole study [25]. The abrasion stroke length, abrasion speed, abrasion duration, and the number of abrasion cycles were kept constant at $76 \mathrm{~mm}, 60$ cycles per minute $(\mathrm{cpm})$, $10 \mathrm{~min}$, and 600 , respectively.

2.4. Experimental Set-Up. Figure 2 shows the scheme of the complete experimental set-up. Particle free air is passed through a nanosecured work post (HPPE 10, Erma Flux S.A., France) [26] containing the Taber abrasion apparatus. This work post has a particle filter efficiency of $99.99 \%$. The test sample is placed inside a self-designed Emission Test Chamber $(0.5 \mathrm{~m} \times 0.3 \mathrm{~m} \times 0.6 \mathrm{~m})$ [27]. A slot is provided on one of the walls of this chamber allowing the horizontal arm of abrasion apparatus passing through and operating the apparatus (equipped with motor) to be placed externally. The sampling of the generated aerosol particles is done in a close proximity of the test sample. The Taber apparatus along with the emission test chamber constitute aerosol generation section. The aerosol particles, getting generated during the abrasion process, are characterized in terms of their number concentration and number size distribution. The aerosol generation section is combined with an aerosol measurement section. It consists of a condensation particle counter (CPC; Model 3775; TSI Inc. USA; measurable size range: $4 \mathrm{~nm}$ to $3 \mu \mathrm{m}$ ), a scanning mobility particle sizer (SMPS: Model DMA 3081 and CPC 3775; TSI Inc. USA; measurable size range: 15 to $500 \mathrm{~nm}$ ), an aerodynamic particle sizer (APS; Model 3321; TSI Inc. USA; measurable size range: 0.5 to $20 \mu \mathrm{m}$ ), and a miniparticle sampler (MPS; Ecomesure Inc. France) [28, 29]. The operation conditions of these instruments are as follows: CPC-flow rate of $1.5 \mathrm{~L} / \mathrm{min}$ with $1 \mathrm{~s}$ of sampling time; SMPSflow rate of $0.3 \mathrm{~L} / \mathrm{min}$ with $120 \mathrm{~s}$ of sampling time; APS-flow rate of $5 \mathrm{~L} / \mathrm{min}$ with $5 \mathrm{~s}$ of sampling time.

A MPS is used for the particle collection through filtration technique on copper mesh grids which can be used later in TEM for various qualitative analyses of the released particles without any limitation on the aerosol size.

Therefore, the whole aerosol measurement section, quantifying the particle release, can measure aerosol particles having sizes ranging from $4 \mathrm{~nm}$ to $20 \mu \mathrm{m}$. The deposition probability of this particle size range varies from 20 to $90 \%$ once they enter inside a human body [30]. The whole experimental set-up, in general, follows the ones used in $[4,31,32]$. For the analysis of the surfaces, a scanning electron microscope (QUANTA ESEM 400, FEI Inc., The Netherlands) has also been used. 


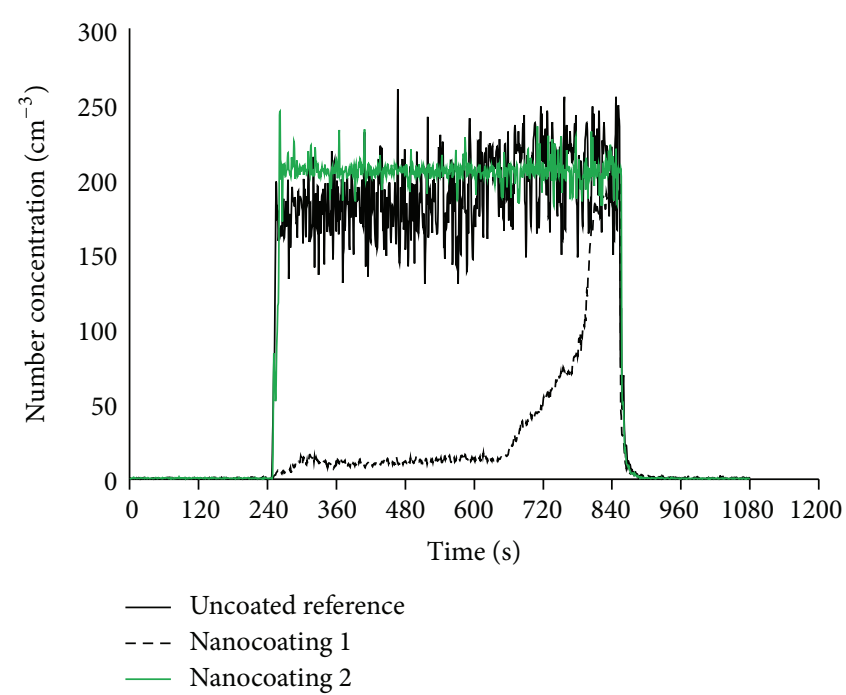

(a)

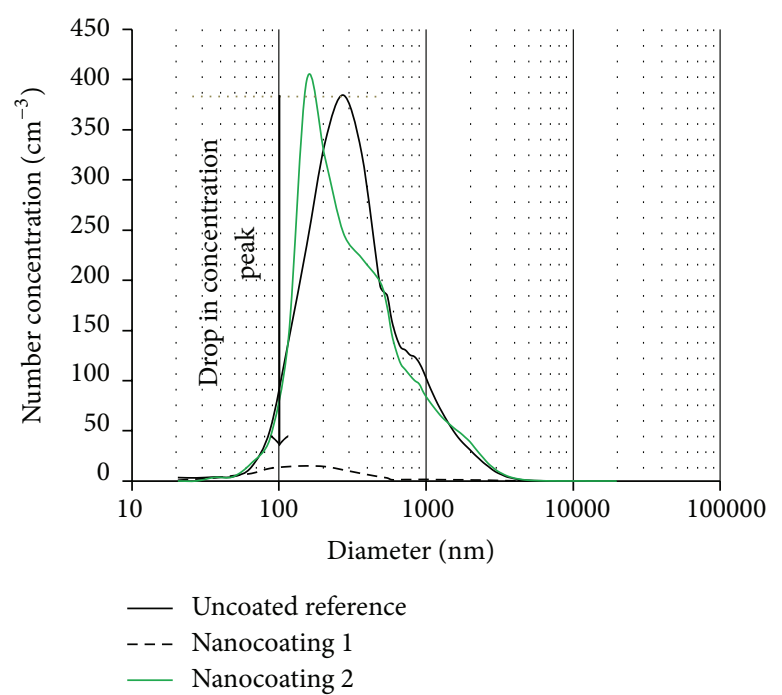

(b)

FIgURE 3: (a) Particle number concentration variation with time. (b) Size distribution of the aerosol particles generated during abrasion of 4 layered nanocoating samples under $6 \mathrm{~N}$ of normal load (note: all the curves are mean curves obtained from 3 repeated tests).

2.5. Background and Particle Loss. Three empty test runs were done before the real experiment to measure the concentration of the background particles and those generated by the abrasion apparatus. The abrasion apparatus was made to operate without the sample present in the chamber. The average concentration detected by CPC was $\sim 0.7 \mathrm{~cm}^{-3}$ with a standard deviation of $0.2 \mathrm{~cm}^{-3}$ in the whole volume. Therefore, the concentrations of all the background particles and those generated by the abrasion apparatus were insignificant. The calculations of the loss of particle concentration due to their deposition on the walls of the chamber have shown a loss of $4 \%$ in number during $10 \mathrm{~min}$ (equal to the duration of the abrasion process).

Along with some turbulence losses, there can be some particle loss in the transport tubes also. These losses have not been taken into account while calculating the particle number concentrations. Hence, the present study is rather semiquantitative.

\section{Results}

3.1. Effect of the Type of Nanocoating. Figures 3(a) and 3(b) compare, through an example, the particle number concentration curves produced when the 4 layered nanocoating test samples were abraded under a normal load of $6 \mathrm{~N}$. The test was repeated thrice under same conditions. For uncoated reference, the repetition was done on the same brick. In Figure 3(a), the abrasion starts at $t=240 \mathrm{~s}$ and ends at $t=$ $840 \mathrm{~s}$. Before and after this time interval ( $t=0$ to $240 \mathrm{~s}$ ), the system is idle.

The nanocoating 2 seems to impart no difference on the aerosol particle release when it is compared with the uncoated reference. The two have almost the same concentration levels. Since the nanocoating 2 probably gets rubbed off completely without providing any resistance, the particle number concentration attains its maximum value $\left(C \approx 200 \mathrm{~cm}^{-3}\right)$ soon after the abrasion starts. The standard deviation ranges from 5 to $16 \mathrm{~cm}^{-3}$.

For nanocoating 1 , the number concentration is initially low $\left(C \approx 14 \mathrm{~cm}^{-3}\right)$ due to a probable resistance of the nanocoating 1 against abrasion. However, this resistance continues up to a certain point $(t=624 \mathrm{~s})$ after which the nanocoating 1 may start getting rubbed off. As a result, the number concentration starts increasing gradually. It attains the same value as for nanocoating 2 or the reference towards the end of the abrasion. The standard deviation in the values measured for nanocoating 1 varies from 0.7 to $27 \mathrm{~cm}^{-3}$.

In Figure 3(b), the particle size distribution of the released aerosol particles, during the abrasion process, is shown. The nanocoating 2 seems to have no effect on the size distribution too. However, there is a shift of the size mode towards smaller particle sizes $(154 \pm 10 \mathrm{~nm})$. The standard deviation in the particle size distribution values measured for nanocoating 2 changes from 0.2 to $16 \mathrm{~cm}^{-3}$.

The nanocoating 1 considerably drops the peak of the number concentration curve by a factor of $\sim 30$ rendering the particle release totally insignificant. The standard deviation measured here is $8 \mathrm{~cm}^{-3}$ maximum.

In Figures 4(a) and 4(b), general overviews of the released particles are shown which were sampled during first 4 minutes of the abrasion test. A polydispersed aerosol from both nanocoating 1 (Figure $4(\mathrm{a})$ ) and nanocoating 2 (Figure $4(\mathrm{~b})$ ) can be seen on the mesh grid with a high degree of agglomeration. A closer look on the morphology (Figure 4(c) for nanocoating 1 and Figure 4(d) for nanocoating 2) shows irregularly shaped aerosol particles having size ranging from hundreds of nanometer to tens of micrometer. The chemical analysis of these aerosol particles was found to have a Ti content of $1.5-3.5 \%$ (in mass) for both nanocoatings. However, 


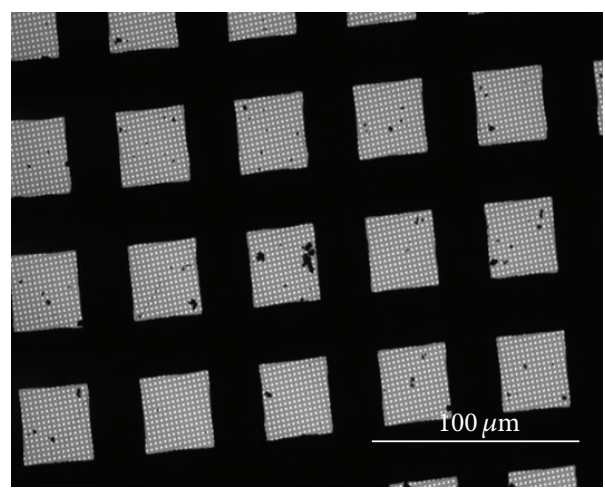

(a)

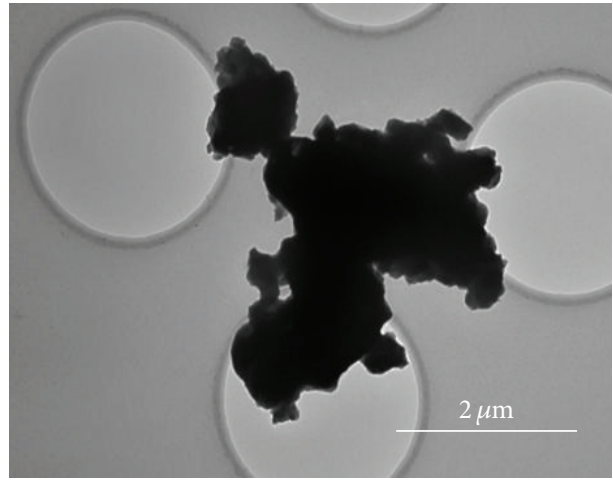

(c)

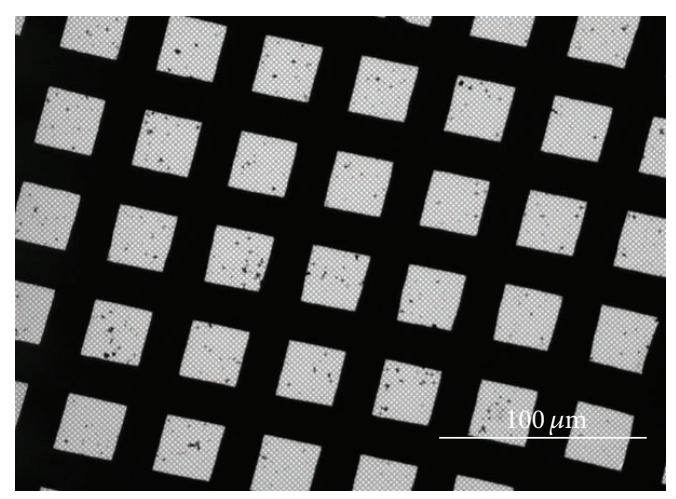

(b)

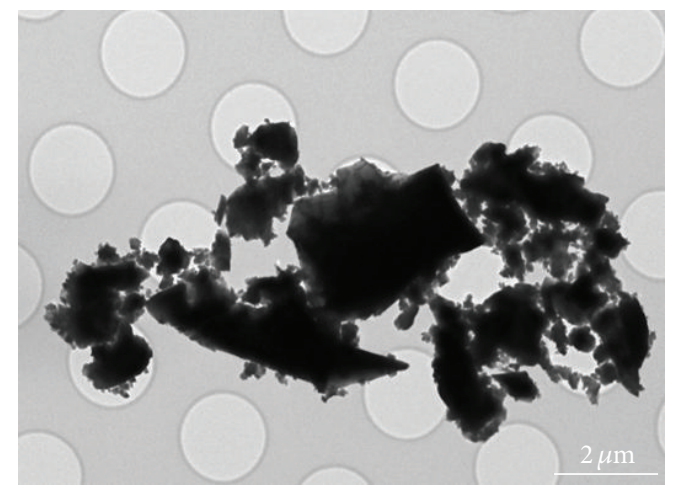

(d)

FIGURE 4: TEM image of the aerosol particles generated from (a) and (c) nanocoating 1 and (b) and (d) nanocoating 2.

the released aerosol particles from nanocoating 2 were found to be dominated by $\mathrm{Si}$ ( $50-70 \%$ in mass; essentially coming from the brick and the abradant), C (5-7\% in mass; essentially coming from the nanocoating 2 copolymer), and $\mathrm{Al}$ (10-20\%; essentially coming from the brick). In case of nanocoating 1 , Al was completely missing from the elemental composition of the released aerosol particles and the $\mathrm{C}$ content was elevated by $4-5 \%$.

Therefore, from these observations, one can say that in case of nanocoating 1 , the release of the aerosol particles was entirely contributed by nanocoating 1 itself. No particles came from the brick underneath. But for nanocoating 2, presence of the $\mathrm{Al}$ shows that the aerosol particles came from the brick too after the nanocoating 2 deterioration. It should be noted that for both nanocoatings, no free particles of $\mathrm{TiO}_{2}$ were found on the grid. In fact, they were found to be embedded inside the copolymer matrix of the nanocoatings.

3.2. Effect of the Normal Load. In Figure 5(a), effect of increasing normal load has been shown on a 4 layered nanocoating 1 sample. The abrasion commences at $t=240 \mathrm{~s}$ and ends at $t=840 \mathrm{~s}$. For a clear view of the particle number concentrations, between $t=240 \mathrm{~s}$ and $t=480 \mathrm{~s}$, a zoomed view in Figure 5(al) is also shown. The released aerosol particle number concentration is found to be increasing with normal load. The same pattern continues in Figure 5(b) for a 4 layered nanocoating 2 sample too.
While measuring the particle size distribution in case of the nanocoating 1, the SMPS and APS showed very low concentrations which were even close to their particle detection thresholds. Hence, the two particle sizers were not employed further. But for nanocoating 2, there were no such problems. Thus, the size distribution, for nanocoating 2 , is shown in Figure 5(c). Three unimodal distributions with increasing size modes (i.e., $154 \mathrm{~nm}$ to $274 \mathrm{~nm}$ to $365 \mathrm{~nm}$ ) and increasing concentration peaks can be seen for increasing normal loads.

3.3. Effect of the Number of Layers. The number of layers also has a substantial effect on the aerosol particles generation. Figure 6 demonstrates this effect where two samples, having 2 and 4 layers of nanocoating 1, are tested under a normal load of $6 \mathrm{~N}$. The abrasion commences at $t=240 \mathrm{~s}$ and ends at $t=840 \mathrm{~s}$. The released particle number concentration is always lower when a 4 layered sample (std. deviation: 2 to $27 \mathrm{~cm}^{-3}$ ) is abraded as compared to the two layered one (std. deviation: 13 to $37 \mathrm{~cm}^{-3}$ ) or an uncoated reference. Both sets of layers seem to provide resistance towards abrasion. The SEM observations of the 4 layered nanocoating 1 sample were also done at the end of the abrasion. Figure 7 shows the observation. An unabraded coated surface (marked A) had an average Ti content of $\sim 12 \%$ (in mass). For the abraded part (marked B), the average Ti content lowers down to 0\% (in mass), thus, completely exposing the brick surface. However, 


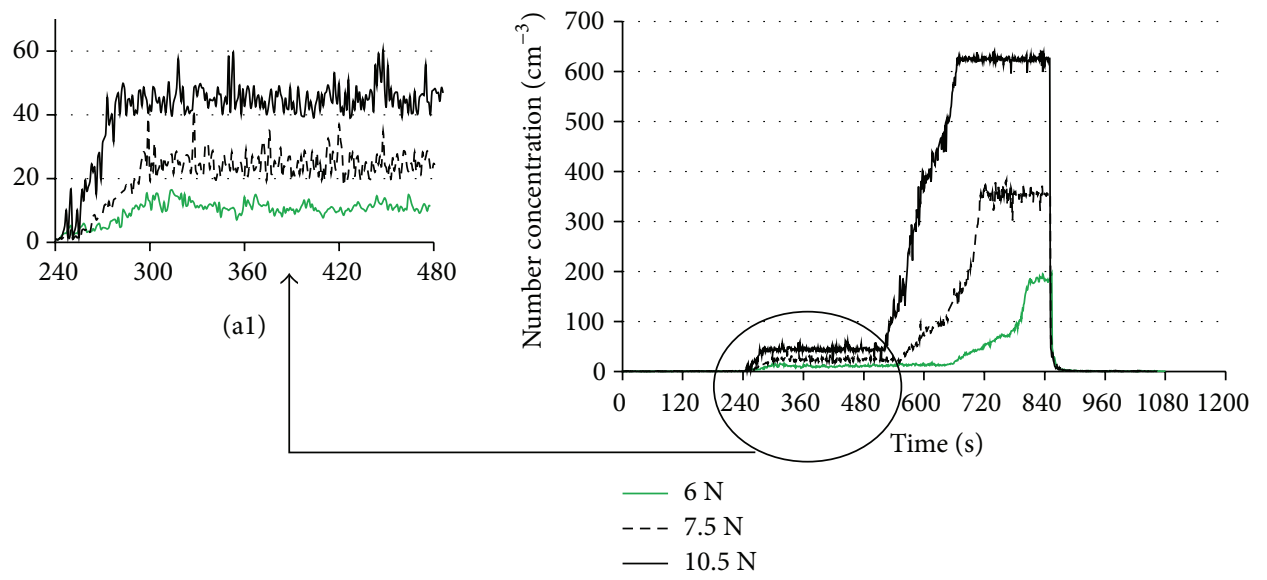

(a)

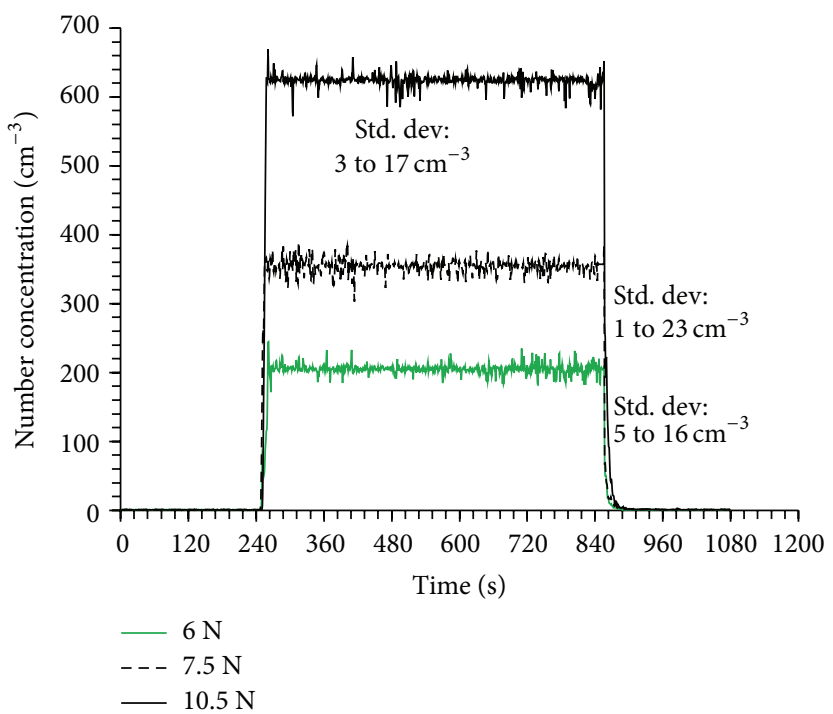

(b)

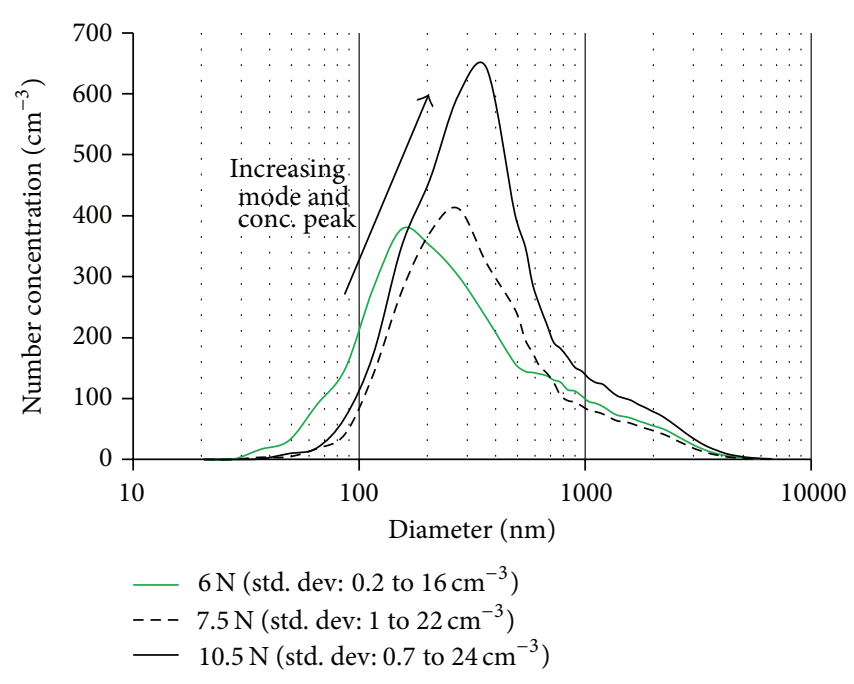

(c)

FIgURE 5: (a) Particle number concentration variation with time for 4 layered nanocoating 1 and (b) nanocoating 2 sample; (al) zoomed view; (c) size distribution of the aerosol particles generated during abrasion of 4 layered nanocoating 2 sample (note: all the curves are mean curves obtained from 3 repeated tests).

in the case of nanocoating 2, both 2 and 4 layered samples had similar particle number concentrations.

\section{Discussion}

The particle number concentration $(\# C)$ variations with time $(t)$, shown in Figures 3(a) and 5(a), can be modeled in the forms shown in Figure 8 where Figure 8(a) corresponds to the uncoated reference, Figure 8 (b) corresponds to the nanocoating 1, and Figure 8 (c) corresponds to the nanocoating 2. Considering Figure 8(b), the curve for particle number concentration variation is constituted of 5 segments marked as EF, FG, GH, HI, and IJ.

The abrasion process starts at point E. As a result, \#C starts rising from point $\mathrm{E}$ and stops at point $\mathrm{F}$. This phase can be termed as phase I. During this phase, the contact surface conditions between the abradant and the nanocoating are believed to evolve due to changing surface roughness during abrasion. This evolution (marked as $\left.\left(\Delta C_{1} / \Delta t\right)_{\mathrm{I}}\right)$ continues until the two surfaces come in equilibrium with each other which corresponds to point F. From the point $\mathrm{F}$ to the point $\mathrm{G}$, \#C remains constant, that is, phase II. During this phase, the abrasion of the nanocoating is being done under an equilibrium or stationary state and the nanocoating is still in a stable state. The EDX analysis of the nanocoating surface during this phase showed a strong presence of 5-8\% (in mass) of Ti. There is some Ti content ( $\sim 3.5 \%$ (in mass)) with no $\mathrm{Al}$ content in the sampled aerosol particles too (Figure 4(c)). From point $\mathrm{G}$, \#C rises again to the point $\mathrm{H}$, that is, phase III. In this phase, the deterioration of the nanocoating is believed to start. The duration of this phase is decided by the level of the resistance a nanocoating can provide against its deterioration. Beyond point $\mathrm{H}$, \#C gets saturated and drops at point I (phase IV), where the abrasion stops. The nanocoating 


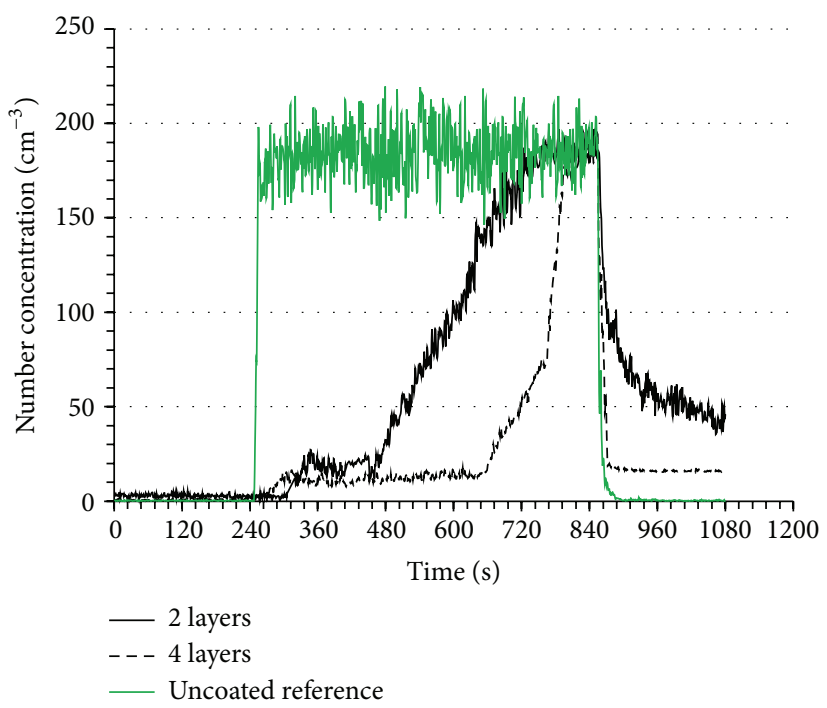

FIGURE 6: Particle number concentration variation with time for 2 and 4 layered nanocoating 1 samples (note: all the curves are mean curves obtained from 3 repeated tests).

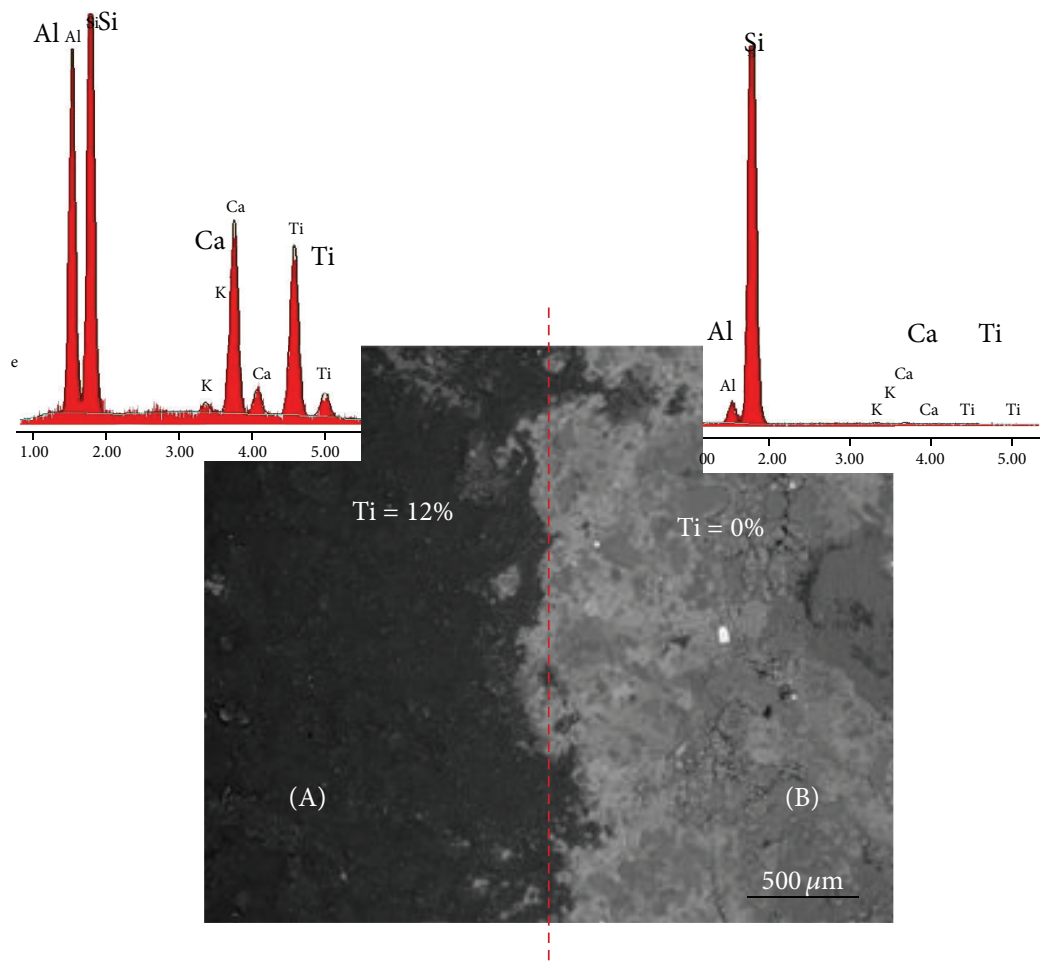

FIGURE 7: SEM image and EDX analysis of the coated and abraded parts of the nanocoating 1 sample; part (A): unabraded coated surface; part (B): abraded.

is supposed to be completely deteriorated during phase IV and the brick surface is exposed. The SEM of the brick surface done during this phase (Figure 7) shows a complete absence of Ti.

From these interpretations, since nanocoating 2 does not provide any resistance against abrasion and gets rubbed off easily, it appears that the phases II and III are totally absent for nanocoating 2 and uncoated sample and longer phases $I$ and $I V$ seem to compensate for their absence. The same can be seen in Figures 8(a) and 8(c). If the subscript " 0 " signifies the uncoated reference, subscript " 1 " signifies the nanocoating 1 and subscript " 2 " signifies nanocoating 2 , then one can deduce Table 3 where 8 segments (from Figure 8 ) are represented in the terms of 8 concentration measures. 
TABLE 3: Representation of segments from Figure 8 in terms of concentration measures.

\begin{tabular}{lcccccccc}
\hline Segment & $\mathrm{AB}$ & $\mathrm{BC}$ & $\mathrm{EF}$ & $\mathrm{FG}$ & $\mathrm{GH}$ & $\mathrm{HI}$ & $\mathrm{KL}$ & LM \\
\hline Representation & $\left(\frac{\Delta C_{0}}{\Delta t}\right)_{\mathrm{I}}$ & $\left(C_{0}\right)_{\mathrm{IV}}$ & $\left(\frac{\Delta C_{1}}{\Delta t}\right)_{\mathrm{I}}$ & $\left(C_{1}\right)_{\mathrm{II}}$ & $\left(\frac{\Delta C_{1}}{\Delta t}\right)_{\mathrm{III}}$ & $\left(C_{1}\right)_{\mathrm{IV}}$ & $\left(\frac{\Delta C_{2}}{\Delta t}\right)_{\mathrm{I}}$ & $\left(C_{2}\right)_{\mathrm{IV}}$ \\
\hline
\end{tabular}

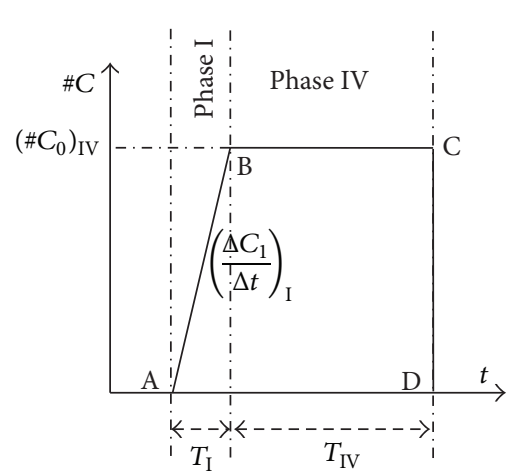

(a)

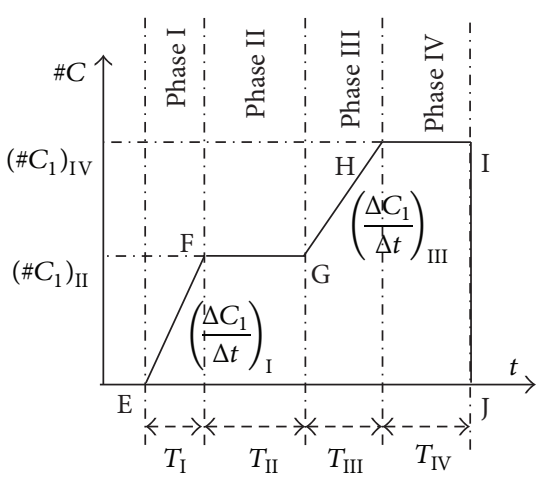

(b)

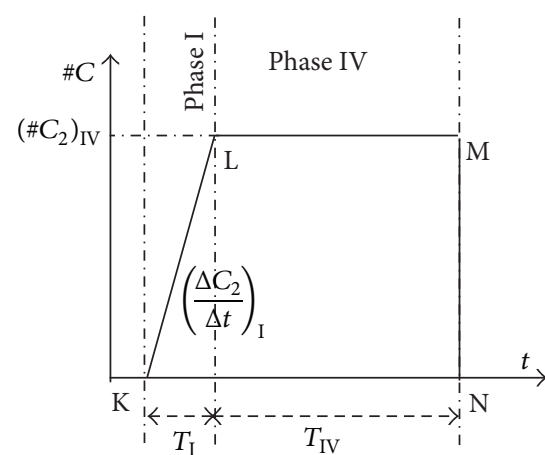

(c)

FIGURE 8: Generalized forms of the variation of aerosol particle number concentration generated from (a) uncoated reference (b) nanocoating 1 and (c) nanocoating 2.

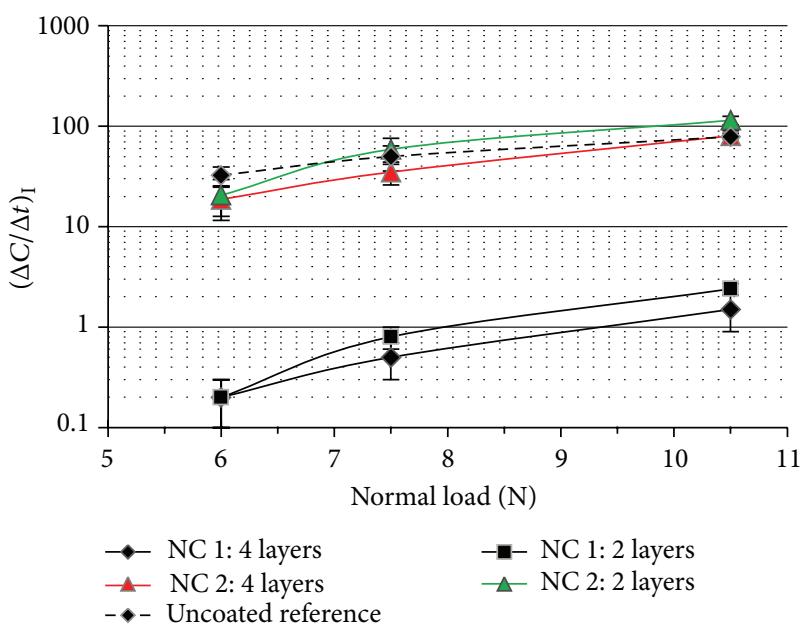

(a)

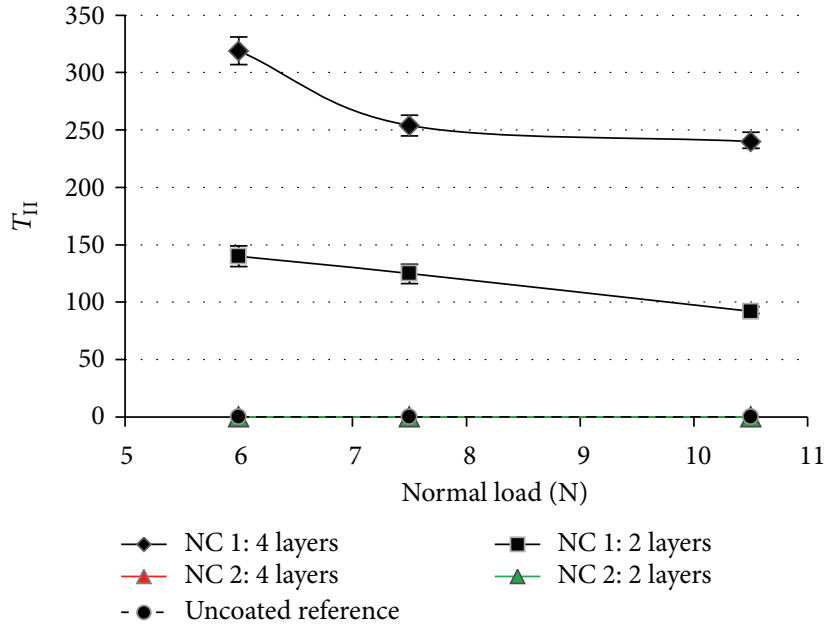

(b)

FIGURE 9: (a): Rate of change of the number concentration as a function of the normal load during phase I; (b) phase II duration as a function of the normal load for all nanocoating samples (note: all the curves are mean curves obtained from 3 repeated tests).

In Table 4, the values of these concentration measures are mentioned which were evaluated for all test samples and three normal load values. $T_{i}$ is the duration of occurrence of the $i$ th phase ( $i=\mathrm{I}$, II, III, IV). On the basis of this table, it can be said that irrespective of the normal load acting during abrasion, $\left(\Delta C_{0} / \Delta t\right)_{\mathrm{I}}>\left(\Delta C_{1} / \Delta t\right)_{\mathrm{I}} ;\left(\Delta C_{2} / \Delta t\right)_{\mathrm{I}}>\left(\Delta C_{1} / \Delta t\right)_{\mathrm{I}}$; $\left(\Delta C_{1} / \Delta t\right)_{\mathrm{I}}<\left(\Delta C_{1} / \Delta t\right)_{\mathrm{III}} ;\left(\# C_{0}\right)_{\mathrm{IV}} \approx\left(\# C_{1}\right)_{\mathrm{IV}} \approx\left(\# C_{2}\right)_{\mathrm{IV}}$.

Based on the values obtained in Table 4 , rate of change of the number concentration of the released particles during phase I, $(\Delta C / \Delta t)_{\mathrm{I}}$, can be plotted as a function of the normal load for all test samples. This is shown in Figure 9(a). Similarly, the duration of the phase II ( $T_{\text {II }}$ ) can also be plotted as a function of the normal load (see Figures 9(a) and 9(b)).
From these figures, the curves corresponding to the nanocoating 1 (NC 1:2 layers and NC 1:4 layers) are clearly distinct from those of the nanocoating 2 (NC 2:2 layers and NC 2: 4 layers) and the uncoated reference. The nanocoating 1 samples hold the lowest values of $(\Delta C / \Delta t)_{\text {I }}$ with a factor of difference almost equal to 100 . This demonstrates their high resistance towards abrasion. At the same time, the nanocoating 1 samples hold the highest values for $T_{\text {II }}$ also which demonstrates the highest duration of the stability of the nanocoating 1 during abrasion. This stability increases with the increase in number of nanocoating layers and decreases with the increase in normal load. The nanocoating 2 and the uncoated reference samples have $T_{\text {II }}=0$. 


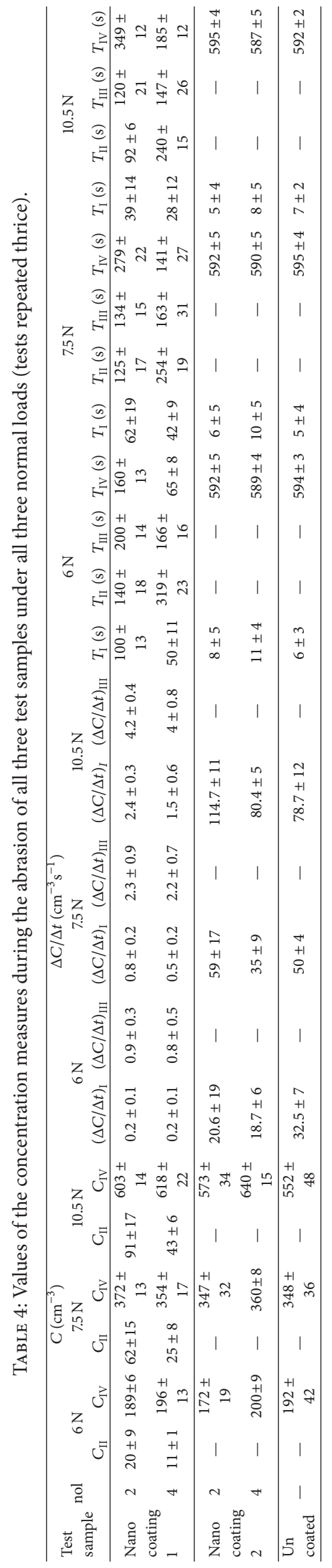


Therefore, the two quantities $-(\Delta C / \Delta t)_{\mathrm{I}}$ and $T_{\mathrm{II}}-$ can be used as the indicators for the measurement of the particle release tendency of a nanocoating subjected to the abrasion. A more stable (i.e., high $T_{\text {II }}$ ) and lesser deterioration prone (i.e., low $\left.(\Delta C / \Delta t)_{\mathrm{I}}\right)$ nanocoating yields lesser particle release. The $T_{\text {II }}$ can be as high as the duration of the stress application $\left(319 \mathrm{~s}\right.$ in the present case) and $(\Delta C / \Delta t)_{\mathrm{I}}$ can be as low as 0 $\left(0.2 \mathrm{~cm}^{-3} \mathrm{~s}^{-1}\right.$ in the present case $)$.

\section{Conclusion}

This study has investigated the possibility of the release of aerosol nanoparticles from two commercially available $\mathrm{TiO}_{2}$ photocatalytic nanocoatings under mechanical stress conditions, simulated using an abrasion process.

The 4 layered nanocoating 1 sample has performed best in inhibiting the particle release, followed by the 2 layered one. However, the nanocoating 2 has not succeeded at all in its inhibition (Figures 3, 5, and 6).

The chemical analysis of the released aerosol particles has shown that, owing to a fast deterioration of the nanocoating 2 , the particles were essentially contributed by the brick rather than the nanocoating 2 during abrasion. But in the case of nanocoating 1 , it is the other way around.

No free nanoparticles of $\mathrm{TiO}_{2}$ were found to be present among the released aerosol.

Four different phases during the particle release have been identified and evaluated for all three test samples (Figure 8, Tables 3 and 4).

The two particle release indicators $-(\Delta C / \Delta t)_{\mathrm{I}}$ and $T_{\mathrm{IV}}-$ have been introduced which can be used for measuring the holding strength or particle release tendency of a nanocoating (Figure 9).

Further tests shall be done with other nanocoating samples and normal load values to develop a standard test procedure for measuring $(\Delta C / \Delta t)_{\mathrm{I}}$ and $T_{\mathrm{IV}}$. These tests shall be accompanied by other analytical tests too to further strengthen the support for the complete physical interpretations of the four phases.

\section{Conflict of Interests}

The authors declare that there is no conflict of interests regarding the publication of this paper.

\section{Acknowledgments}

The authors would like to thank the French Ministry of Environment (DRC 33 and Program 190), ANSES (Nanodata Project, APR ANSES 2012), and SERENADE for financing the work and are equally grateful to O. Aguerre Chariol, Patrice Delalain, Emmanuel Peyret, and Morgane Dalle for their support during the study.

\section{References}

[1] M. Stamate and G. Lazar, "Application of titanium dioxide photocatalysis to create self-cleaning materials," Romanian
Technical Sciences Academy MOCM, vol. 13, no. 3, pp. 280-285, 2007.

[2] A. Fujishima, K. Hashimoto, and T. Watanabe, $\mathrm{TiO}_{2}$ Photocatalysis: Fundamentals and Applications, BKC, Tokyo, Japan, 1st edition, 1999.

[3] F. P. Torgal and S. Jalali, "Eco-efficient construction and building materials," Construction and Building Materials, vol. 25, no. 2, pp. 582-590, 2011.

[4] M. Vorbau, L. Hillemann, and M. Stintz, "Method for the characterization of the abrasion induced nanoparticle release into air from surface coatings," Journal of Aerosol Science, vol. 40, no. 3, pp. 209-217, 2009.

[5] S. Suzuki and E. Ando, "Abrasion of thin films deposited onto glass by the Taber test," Thin Solid Films, vol. 340, no. 1, pp. 194200, 1999.

[6] N. Shandilya, O. le Bihan, and M. Morgeneyer, "A review on the study of the generation of (nano) particles aerosols during the mechanical solicitation of materials," Journal of Nanomaterials, vol. 2014, Article ID 289108, 16 pages, 2014.

[7] M. M. Hassan, H. Dylla, L. N. Mohammad, and T. Rupnow, "Evaluation of the durability of titanium dioxide photocatalyst coating for concrete pavement," Construction and Building Materials, vol. 24, no. 8, pp. 1456-1461, 2010.

[8] D. Gohler, M. Stintz, L. Hillemann, and M. Vorbau, "Characterization of nanoparticle release from surface coatings by the simulation of a sanding process," Annals of Occupational Hygiene, vol. 54, no. 6, pp. 615-624, 2010.

[9] A. T. Saber, I. K. Koponen, K. A. Jensen et al., "Inflammatory and genotoxic effects of sanding dust generated from nanoparticle-containing paints and lacquers," Nanotoxicology, vol. 6, no. 7, pp. 776-788, 2012.

[10] P. C. Raynor, J. I. Cebula, J. S. Spangenberger, B. A. Olson, J. M. Dasch, and J. B. D'Arcy, "Assessing potential nanoparticle release during nanocomposite shredding using directreading instruments," Journal of Occupational and Environmental Hygiene, vol. 9, no. 1, pp. 1-13, 2012.

[11] J. Lee, S. Mahendra, and P. J. J. Alvarez, "Nanomaterials in the construction industry: a review of their applications and environmental health and safety considerations," ACS Nano, vol. 4, no. 7, pp. 3580-3590, 2010.

[12] O. le Bihan, N. Shandilya, L. Gheerardyn, O. Guillon, E. Dore, and $\mathrm{M}$. Morgeneyer, "Investigation of the release of particles from a nanocoated product," Advances in Nanoparticles, vol. 2, pp. 39-44, 2013.

[13] J. Petkovic, B. Zegura, M. Stevanovic et al., "DNA damage and alterations in expression of DNA damage responsive genes induced by $\mathrm{TiO}_{2}$ nanoparticles in human hepatoma HepG2 cells," Nanotoxicology, vol. 5, no. 3, pp. 341-353, 2011.

[14] J. Unnithan, M. U. Rehman, F. J. Ahmad, and M. Samim, "Aqueous synthesis and concentration-dependent dermal toxicity of $\mathrm{TiO}_{2}$ nanoparticles in Wistar rats," Biological Trace Element Research, vol. 143, no. 3, pp. 1682-1694, 2011.

[15] D. B. Warheit, W. J. Brock, K. P. Lee, T. R. Webb, and K. L. Reed, "Comparative pulmonary toxicity inhalation and instillation studies with different $\mathrm{TiO}_{2}$ particle formulations: impact of surface treatments on particle toxicity," Toxicological Sciences, vol. 88, no. 2, pp. 514-524, 2005.

[16] ASTM International, "Standard test method for the abrasion of organic coatings by the Taber abradant," ASTM D4060, 2007.

[17] ASTM International, "Standard test methods for dry abrasion mar resistance of high gloss coatings," ASTM D6037, 1996. 
[18] ASTM International, "Standard test method for resistance of transparent plastics to surface abrasion," ASTM D1044, 2008.

[19] L. Golanski, A. Guiot, M. Pras, M. Malarde, and F. Tardif, "Release-ability of nano fillers from different nanomaterials (toward the acceptability of nanoproduct)," Journal of Nanoparticle Research, vol. 14, article 962, 2012.

[20] W. Boentoro, A. Pflug, and B. Szyszka, "Scratch resistance analysis of coatings on glass and polycarbonate," Thin Solid Films, vol. 517, no. 10, pp. 3121-3125, 2009.

[21] S. Sepeur, N. Kunze, B. Werner, and H. Schmidt, "UV curable hard coatings on plastics," Thin Solid Films, vol. 351, no. 1-2, pp. 216-219, 1999.

[22] D. Katsamberis, K. Browall, C. Iacovangelo, M. Neumann, and H. Morgner, "Highly durable coatings for automotive polycarbonate glazing," Progress in Organic Coatings, vol. 34, no. 1-4, pp. 130-134, 1997.

[23] A. Wank, B. Wielage, H. Pokhmurska, E. Friesen, and G. Reisel, "Comparison of hardmetal and hard chromium coatings under different tribological conditions," Surface and Coatings Technology, vol. 201, no. 5, pp. 1975-1980, 2006.

[24] C.-Y. Huang and C.-I. Tseng, "The effect of interface modification between POM and PTFE on the properties of POM/PTFE composites," Journal of Applied Polymer Science, vol. 78, no. 4, pp. 800-807, 2000.

[25] M. Morgeneyer, N. Shandilya, Y.-M. Chen, and O. le Bihan, "Use of a modified Taber abrasion apparatus for investigating the complete stress state during abrasion and in-process wear particle aerosol generation," Chemical Engineering Research and Design, 2014.

[26] M. Morgeneyer, O. Le Bihan, A. Ustache, and O. AguerreChariol, "Experimental study of the aerosolization of fine alumina particles from bulk by a vortex shaker," Powder Technology, vol. 246, pp. 583-589, 2013.

[27] O. Le Bihan, M. Morgeneyer, N. Shandilya, O. A. Chariol, and C. Bressot, Handbook on Safe Use of Nanomaterials Chapter 7.2: Emission Chambers, A Method for Nanosafety, Academic Press, San Diego, Calif, USA, 2014.

[28] B. R'mili, O. le Bihan, C. Dutouquet, O. Aguerre-Charriol, and E. Frejafon, "Particle sampling by TEM grid filtration," Aerosol Science and Technology, vol. 47, no. 7, pp. 767-775, 2013.

[29] http://www.ecomesure.com/Mini-Particle-Sampler-MPS-p116-c-8-sc-19.html.

[30] G. Oberdörster, E. Oberdörster, and J. Oberdörster, "Nanotoxicology: an emerging discipline evolving from studies of ultrafine particles," Environmental Health Perspectives, vol. 113, no. 7, pp. 823-839, 2005.

[31] I. K. Koponen, K. A. Jensen, and T. Schneider, "Sanding dust from nanoparticle-containing paints: physical characterisation," Journal of Physics: Conference Series, vol. 151, no. 1, Article ID 012048, 2009.

[32] A. T. Zimmer and A. D. Maynard, "Investigation of the aerosols produced by a high-speed, hand-held grinder using various substrates," Annals of Occupational Hygiene, vol. 46, no. 8, pp. 663-672, 2002. 

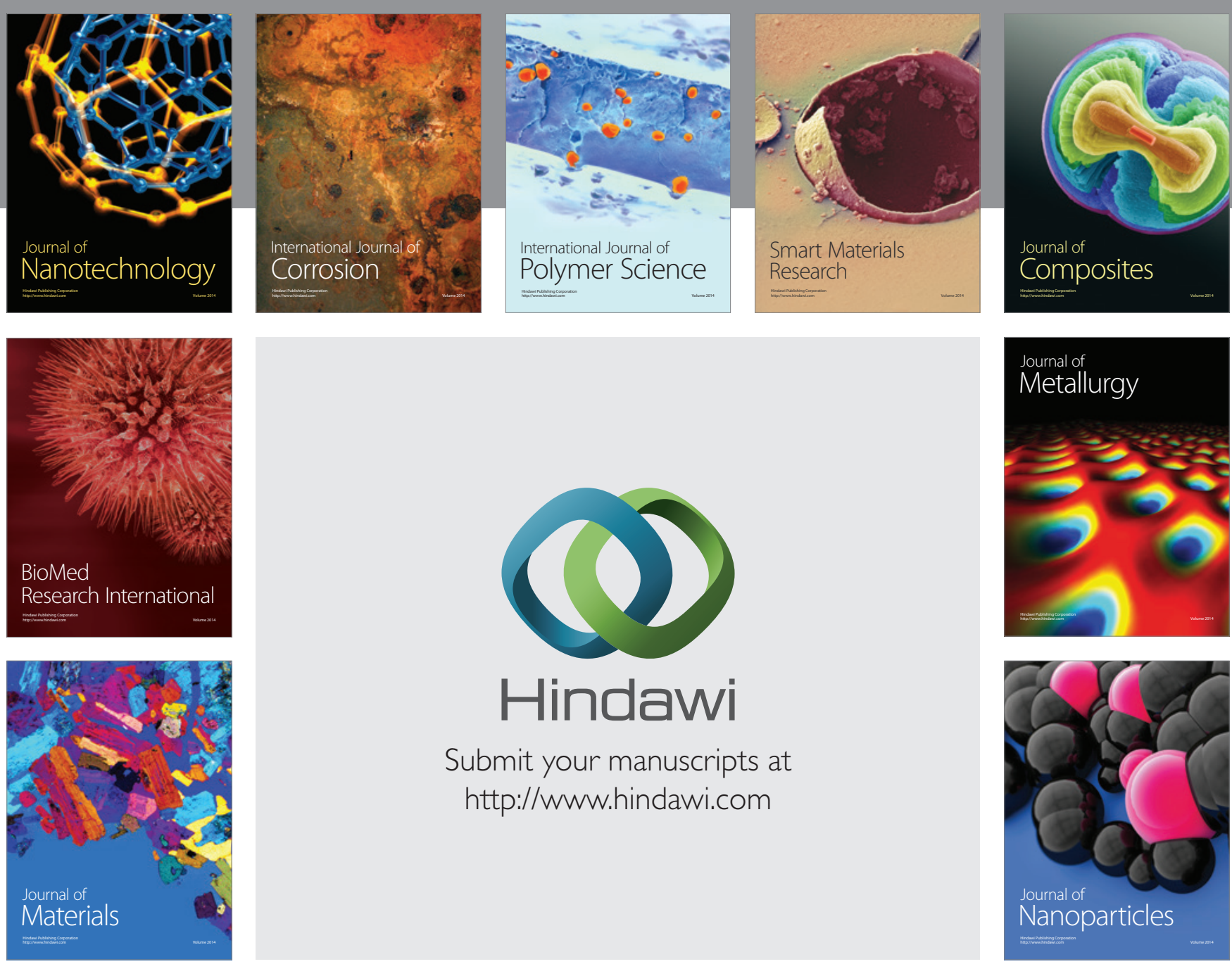

Submit your manuscripts at http://www.hindawi.com
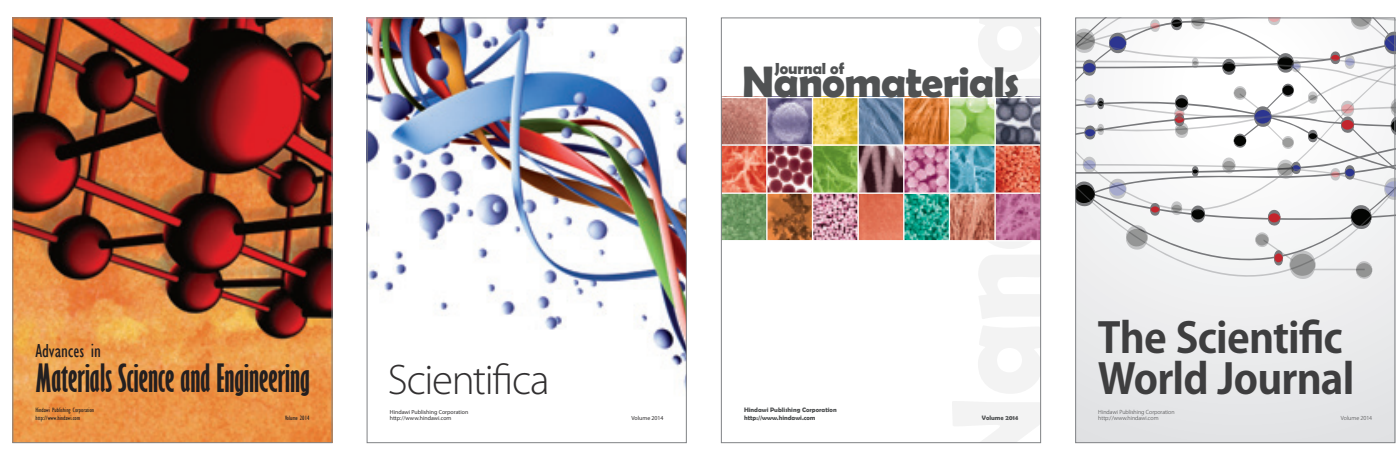

\section{The Scientific World Journal}
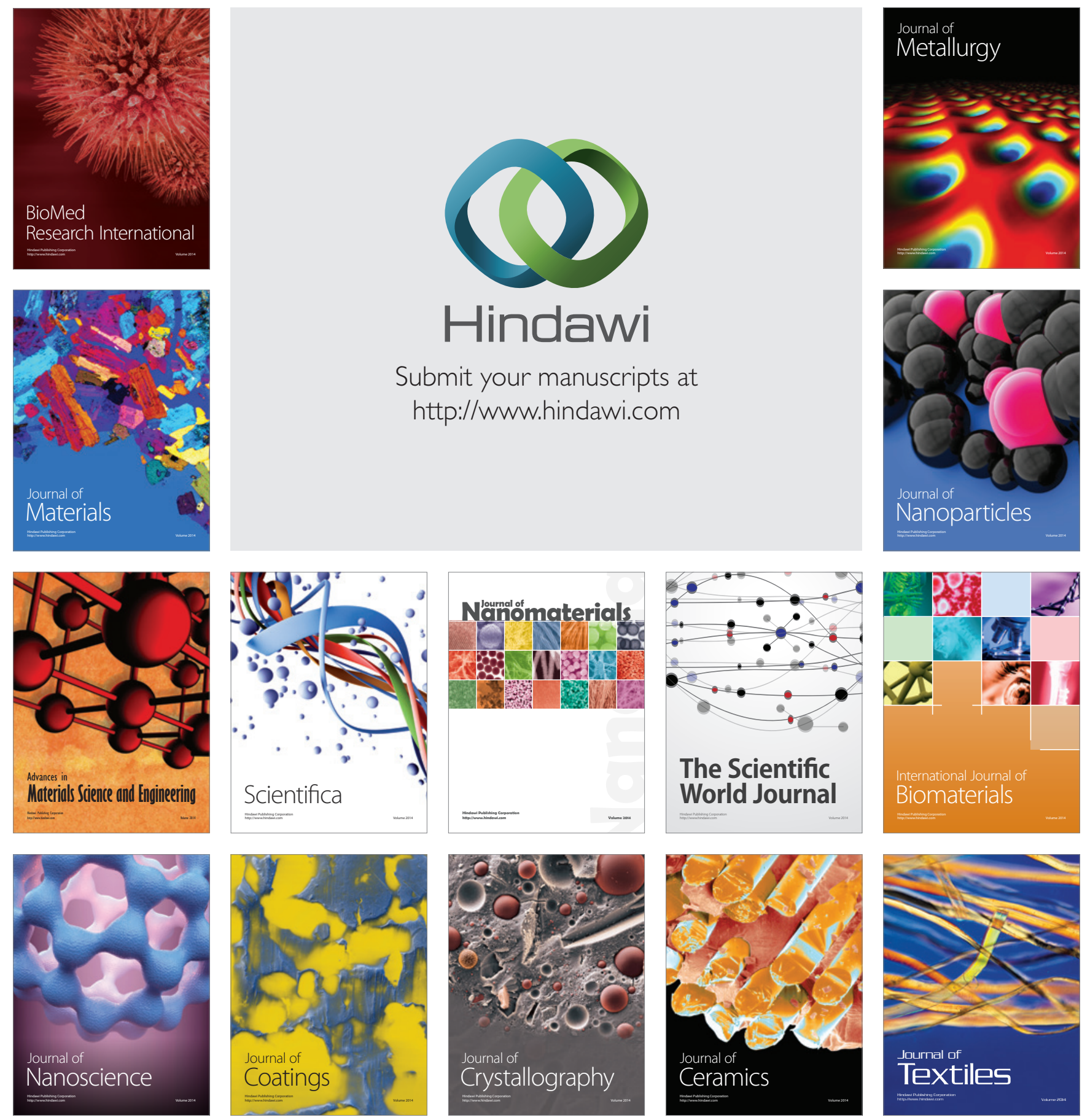